\title{
Creating a Free Painting Situation in the Landscape Painting Course
}

\author{
S.S. TAO \\ School of Arts, Huangshan University, Huangshan, China
}

\begin{abstract}
The landscape painting course is an important element of fine arts teaching in colleges. While the traditional teaching methods gradually fade out, the modern teaching model has not been fully established. This paper discusses the possibility of fostering art students' accomplishments from the perspective of the teaching of landscape painting. It also proposes the teaching idea of creating a free painting environment for art students based on the relationship between traditional teaching and the current trend with the attempt to change the perspective of previous teaching and in hope of enabling students to improve their painting ability and foster necessary aesthetic accomplishments through exposure to art in a natural environment.
\end{abstract}

KEYWORD: Landscape painting course; Free Painting; Natural situation; Aesthetic accomplishments

\section{INTRODUCTION}

Landscape paintings are portraits of landscapes. They are not only an exhibition of beautiful natural scenery, but also an expression of the painters' longing for a good life or appeal for human emotions. Viewers experience the painters' moods by appreciating landscape paintings and become involved in an emotional resonance, making landscape paintings popular. As a basic course in painting and art design, the landscape painting course draws much attention among art schools. Through the teaching of the landscape painting course, the students approach the nature and learn painting skills in nature, improving their painting level and aesthetic taste. The teaching of the landscape painting course not only requires students to objectively describe natural scenery, but also requires them to observe and paint on the basis of their understanding and mastery of art (Zaman, L., Ofria, C, Lenski, R.E. 2012). Different students have their respective unique perspectives of observation and experiences of emotions for the same object, so their painting styles also differ. Currently, domestic colleges have attached varying importance to the landscape painting course, and students also differ in their landscape painting ability (Li, X.X, Li, Y. 2007). Therefore, how to effectively teach the landscape painting course in colleges has become a concern among educators.

With the progress of urbanization, both Constable's pastoral beauty and Ma Yuan's delight in go fishing in a chilling river have already been replaced by crisscross overpasses and the rumbles of motors, and classical "landscapes" have faded away from people's mind. The teaching of landscape painting also faces the same predicament. How to face reality and tradition and how to develop a teaching model for landscape painting that can adapt to today's society are urgent issues concerning art education.

\section{CREATING A FREE PAINTING SITUATION FOR ART STUDENTS}

The teaching objective of the landscape painting course for art college students should not be limited to the training in landscape painting skills, but should focus on fostering students' accomplishments in free painting. Because it is impossible to make clear judgments about the effects of factors such as the angle and lighting of each landscape, teachers are unable to propose specific requirements for composition, color, and strokes (Li, P., Mei, S.D. 2009). The students also have different viewing moods and feelings every moment of every day. Therefore, the painting effect (or the degree of completion) should not be considered the sole criterion for evaluating results. The learning of landscape painting based on landscapes helps grasp the colors and shapes of objects from the perspective of painting skills but tends to result in ignorance of 
students' true feelings about landscapes in their mind, which is the soul of art creation.

Different from indoor courses, students' cognition of landscapes has two characteristics: (i) They feel the wide color variations of nature and attempt to learn painting skills; (ii) They need to quickly summarize and extract images and organize colors in outdoor environments.

Only by focusing on fostering art students' accomplishments in free painting will it be possible for landscape painting to open students' mind, which is also a reflection of the spirit of academic freedom. The students' mind should be developed not by imposing a model upon them but by providing a situation allowing them to release perception and thinking. The teachers should inspire mental growth in the students. The seemingly "serious" teaching behavior which requires students to describe in vivid shapes or takes model paintings of a certain style as the sole criterion, actually deviates from the original intention of teaching. The students' mind won't be developed, and they simply master a painting skill. Paintings imply human emotions; however, skills cannot replace emotions but simply means of expressing emotions. Skills themselves have no emotions, and they become meaningful only in terms of guiding the expression of true feelings.

Whether for modeling or for design art, painting in natural and human environments by simulating nature is far from being enough to acquire painting skills. The real purpose of the painting course is to allow students to completely relax themselves in natural environments, enchant themselves with natural environments, release their feelings, and stretch their emotions. A cheerful state of mind is an important factor for motivating students' autonomy. Exerting influence on feelings by looking at natural beauty is a process of travelling ten thousand miles said by ancient people as well as a process of aesthetic education.

Therefore, the focus is on enabling students to carefully look at and paint the rich shapes and colors of objects in nature by closely contacting and communicating with nature and recalling nature with emotions. The students will not only be able to express colors and shapes, but also will become acutely aware of the abundance of colors and the variations in tones. Different ecologies of cultural landscapes in different regions in different seasons have different appearances and give different feelings. These situations can deeply touch students so that they will be able to taste different beauties of forms, tones, and cultural history in natural environments and express models, colors, and designs with distinct personality in their painting and design works.

\section{PROBLEMS EXISTING IN CURRENT TEACHING AND COUNTERMEASURES}

\subsection{The college entrance examination system for admission solely based on scores and the general lack of accomplishments for art students}

Due to admission solely based on scores in the college entrance examination system and the specificity of the entrance examination for art students, art students are in a rapid increase in the reality of enrollment expansion for mass higher education. Those students who originally do not regard art as their career or who are weak in art also apply for admission to art schools in order to go to college, posing a new challenge to colleges' fine arts teaching. These students are generally weak in modeling and inactive in imaginal thinking and have difficulty in learning. For these students, teaching should not rest on the traditional painting or design model but focus on cultivating sensitivity, imagination, and personality. Therefore, the teaching of the current landscape painting course should adapt to the reality of the source of students and shift the focus onto students' mental development, making examination in modeling no longer a psychological burden for art students.

\subsection{The difficulty confronted by traditional teaching: imitation like plagiarism}

Currently, the traditional educational method is still adopted for the landscape painting courses of many colleges, and the teachers require a solid foundation and the students' landscape painting assignments primarily aim to accurately describe objective objects (Sun, M.J., Li, D., Sun, J.Z. 2004). In order to produce desired results, the teachers generally require completion of a considerable number of assignments and think that skills come from practice; or they just let students regardless of specific teaching requirements, making some students who are unconscious turn the practice of landscape painting into a holiday. Some students imitate others' landscape paintings and use them as painting assignments in order to meet the requirements of classroom teaching (the prints of the landscape works painted by successful painters are often sold in places for landscape painting, and some students also download the works similar to the landscapes from the Internet for imitation). Whether in terms of traditional skill training or in terms of modern ability development, such kind of teaching produces some disappointed results. The landscape painting course is offered originally for two purposes: (a) to help students improve their expression of and skills in painting in natural environments; (b) to cultivate students' sentiments 
and allow them to be experienced in pure natural, historical, and cultural environments, which are obviously contradicted by the traditional teaching model. Therefore, the teaching reform in landscape painting is a realistic problem that has to be addressed.

\subsection{The negative effects of "model paintings" and the necessity of personality guidance}

Students should not be guided simply using the traditional teaching model. The teaching and learning of traditional workshop-style crafts can only cause a skill to be inherited and will not help develop students' imagination and creativity, thus being unable to meeting the requirements of today's society for versatile talent. In the seemingly serious teaching, the teachers do model paintings for students. In this case, the students often imitate the paintings, which is a direct and effective method. The result is that after the teachers complete the model paintings, some imitations similar to the styles of the teachers occur, which look great but fail to express the students' true feelings. Some teachers even evaluate students' assignments based on their own styles and taste, and assignments which are similar to the styles of the teachers score high. Teachers can influence students when painting together with students but should not impose their likes and dislikes upon students.

It is essential to fully motivate students to feel natural landscapes. For different feelings revealed, the tones and forms in the paintings also differ. The teachers play the role of a viewer and objectively evaluate students' assignments. This evaluation is the personal feeling of the viewer rather than authoritative judgment. On the basis of teaching students to paint freely, the teachers should provide guidance for the direction and enlighten and advise the students from both macroscopic and microscopic perspectives so that the students' exploratory innovation will not deviate from art.

\section{ORGANIZING STUDENTS' COGNITION AND FEELINGS ACCORDING TO THEIR PAINTING WORKS}

The landscape painting course is primarily taught in rural areas. The students and the teachers paint landscapes outdoors in the daytime, and the teachers evaluate students' assignments at night. The teachers put the students' assignments together and distinguish between the students' assignments and styles. The evaluation of the students' assignments by the teachers at this point will not only affect the students themselves but also other students' understanding of whether the landscape paintings are good or bad and right or wrong. Therefore, it is by no means allowed to measure the students' assignments with one ruler. The teachers can use network resources to prepare for classes, enlighten students using works of different styles and schools in the face of the students' immature assignments, and ask the students to look for answers themselves and make self-evaluation.

The teachers can also advise the students to consult the works of some painters and find out how the structures, tones, and strokes are made. These reference works can be either painted landscapes or pictures of modern designs and daily life. The teachers can ask the students to talk about the aesthetics of abstract art works based on simple Ming dynasty furniture and talk about the leading role of light in paintings, the creation of the saturation and atmosphere of the paintings; and the modeling features of the retro and modern sense conveyed by a fashion magazine based on a photography work so that the students can associate with rich images in the face of different forms of mountains, trees, rivers, and cottages, and have the courage to try to paint them on their limited papers.

\section{TEACHERS' LEADERSHIP AND STUDENTS' ROLE AS A SUBJECT}

Students are the subject in the teaching process. The choice of composition, tones, and details comply with students' own will, and the students create personalized works based on the art works of previous and current masters. The teachers serve as a guide for students to self-exploration, and the teachers are also an active participant who will not deny students' efforts but give feedback on their own feelings from the perspective of a viewer and respect students' personalized creation. Due to the special identity of teachers, both what they say and what they do will influence the students, and they should express their feelings on the basis of respecting the students. Such participation plays a demonstrative role not in the specific forms of paintings but in providing knowledge background and guidance for the direction.

The object of landscape painting is natural scenery, and the teachers are required to make good preparations before classes. The intensive lectures before classes are an important step, in which the teachers explain teaching plans and requirements, introduce the history and style evolution of landscape paintings, and list the books to be read by the students. In the lectures for evaluating students' paintings in painting areas, the teachers ask the students to go over the contents of the list of books and talk about their feelings. 


\section{PERSONALIZED LANDSCAPE PAINTING- FINE ARTS' FATE}

The landscape painting course is not simply a process in which the students walk in the fields with their travelling bags on their back and paint in the face of beautiful scenery. This teaching behavior has been unable to meet the current needs for the fostering of art students. We need to proceed from the perspective of fostering personality and art accomplishments and make landscape painting a process for students to enrich their self-cognition and improve their aesthetic taste so that they can find painting languages and styles with distinct personality, under the inspiration and guidance of the teachers.

\section{REFERENCES}

[1] Zaman, L., Ofria, C, Lenski, R.E. 2012. Finger-painting fitness landscapes: An interactive tool for exploring complex evolutionary dynamics. Proceedings of the 13th International Conference on the Simulation and Synthesis of Living Systems, ALIFE 2012, East Lansing, 19-22 July 2012, 2012. 499-505.

[2] Li, X.X, Li, Y. 2007. Simulation of Chinese ink-wash painting based on landscapes and trees. Second International Symposium on Plant Growth Modeling, Simulation, Visualization and Applications, PMA 2006, Wenzhou, 13-17 November 2006, 328-333.

[3] Li, P., Mei, S.D. 2009. A method based on Chinese landscape painting style of non-photorealistic rendering. 2008 International Workshop on Education Technology and Training and 2008 International Workshop on Geoscience and Remote Sensing, ETT and GRS, Wuhan, 21-22 December 2008, 743-746.

[4] Sun, M.J., Li, D., Sun, J.Z. 2004. Texture synthesis-based system simulation for Chinese landscape painting. Xitong Fangzhen Xuebao, 16(10): 2317-2321. 